\title{
Cinétique de croissance des champignons associés à Ips sexdentatus Boern et Tomicus piniperda L (Coleoptera : Scolytidae) et des réactions de défense des pins sylvestres (Pinus sylvestris $L$ ) inoculés
}

\author{
F Lieutier *, A Yart, J Garcia, M-C Ham \\ INRA, station de zoologie forestière, Ardon, 45160 Olivet, France
}

(Reçu le 15 mai 1989 ; accepté le 28 décembre 1989)

\begin{abstract}
Résumé - A 3 saisons différentes de l'année, 5 espèces de champignons associées à / sexdentatus et $T$ piniperda ont été inoculées à des pins sylvestres. Des rondins fraîchement coupés ont aussi été inoculés au laboratoire, à 1 seule saison. Le suivi pendant 60 j de la cinétique de croissance des réactions de défense, estimées par leur longueur ou par la quantité de résine (quantité totale et concentration), ainsi que la cinétique de croissance des champignons à l'intérieur des réactions, ont permis d'avancer diverses hypothèses quant au fonctionnement des relations pin sylvestre-scolytides-champignons. Le rôle potentiel de chacun des champignons dans l'induction des réactions de défense, ou dans la mort des arbres lorsque ceux-ci sont attaqués par les scolytes, est discuté. La réaction aurait pour rôle de stopper ou de fortement ralentir la croissance de ces champignons, en attendant que le bourrelet cicatriciel isole complètement les tissus agressés. La longueur de la réaction dans le phloème serait conditionnée par les capacités de diffusion de l'éliciteur, alors que la quantité de résine accumulée dépendrait de la quantité d'éliciteur. L'arrêt de l'accumulation de la résine en un lieu donné ne serait pas dû à la saturation des tissus, mais à un arrêt de l'élicitation en ce lieu. Après la fin de la croissance de la réaction, il y aurait homogénéisation de la répartition de la résine à l'intérieur des tissus concernés, par diffusion de la résine des zones à concentration élevée vers les zones à concentration plus faible et, dans certains cas, par continuation de la synthèse résinique. II est aussi proposé de définir 3 paramètres représentatifs de la réaction : rapidité, intensité, efficacité.
\end{abstract}

Leptographium wingfieldii / Ophiostoma minus / Ophiostoma ips / Ophiostoma brunneo-ciliatum / Hormonema dematioides / résine / résistance / éliciteur / cicatrisation / agressivité / réaction induite

Summary - Kinetics of growth of fungi associated with Ips sexdentatus and Tomicus piniperda (Coleoptera: Scolytidae) and of the defence reaction of the inoculated scots pines. At 3 different seasons in the year, 5 species of fungi associated with I sexdentatus and T piniperda were inoculated into scots pine trees. Logs were also inoculated once during the year in the lab. The reactions were estimated by their length and by the quantity of resin (both total and concentration). The percentage of sieve cells filled with resin was appreciated by histological sections made in each reaction, at 10 and $30 \mathrm{~mm}$ from the point of inoculation and in the middle between this point and the end of the reaction. The kinetics of growth of the fungi and of the defence reactions (length, resin, histology) were followed for 60 days. The temperature and defence reactions were not sufficient to explain the differences in the kinetics of growth between fungi and between seasons (figs 1 and 7). Factors related to intrinsic characteristics of the fungi and to physiological state of the tree may play a role. The possible role of each fungus is discussed according to the induction of the reaction and to tree death when attacked by bark beetle populations. The wound periderm does not seem to be directly responsible for stopping the fungal growth. In return, the considerable slowing down of this growth, followed by a slowing down of the development of the reaction length (fig 3) may give sufficient time for the wound periderm to be built, to insulate the wounded tissues completely and to contain the aggressors. The parallel between the kinetics of growth of the fungi and the kinetics of resin accumulation suggests that the quantity of resin would depend upon the quantity of elicitor produced during the fungal growth. The reaction length in the phloem would depend on the diffusion ability of the elicitor. The end of the resin accumulation at a given place would not depend upon tissue saturation, but rather on the end of the elicitation at this place (compare figs 3, 5 and table III). After the end of the reaction growth, an homogenization process of the resin distribution may take place inside the reaction, by a diffusion of the resin from the highly concentrated zones to the less concentrated zones and, in some cases, by a continuation of the resin synthesis. A definition of 3 parameters representative for the defence reaction is proposed: speed, intensity, efficiency.

Leptographium wingfieldii / Ophiostoma minus / Ophiostoma ips / Ophiostoma brunneo-ciliatum / Hormonema dematioides / resin / resistance / elicitor / scarring / agressivity / induced reaction

\footnotetext{
* Correspondance et tirés à part
} 


\section{INTRODUCTION}

Les champignons phytopathogènes associés aux scolytides attaquant les conifères sont souvent considérés comme les inducteurs de la réaction résinique locale violente qui suit la pénétration de ces insectes dans le phloème des arbres. On a aussi fréquemment attribué à ces champignons la responsabilité de la mort des arbres attaqués par ces ravageurs. Ces micro-organismes occuperaient donc une place privilégiée dans les interactions conifères-scolytides et, d'après les études réalisées en Amérique du Nord et en Norvège, ils joueraient selon les cas un rôle plus ou moins fondamental dans les mécanismes d'installation des populations de scolytides sur leur hôte. La réussite de l'installation des agresseurs dépendrait de l'issue d'une compétition entre les champignons et les insectes d'une part, le développement de la réaction induite de l'arbre d'autre part (Reid et al, 1967; Berryman, 1972; Safranyik et al, 1975; Christiansen, Horntvedt, 1983; Horntvedt et al, 1983; Raffa, Berryman, 1983; Lorio, Hodges, 1985; Lorio, 1986).

Lors de nos premières investigations sur les relations scolytides-pins européens, nous avons identifié les principales espèces de champignons à potentialités phytopathogènes associées à lps sexdentatus Boern et Tomicus piniperda L, comparé leurs fréquences d'association et testé leur agressivité pour le pin sylvestre (Lieutier et al, 1989 b). Nous avons aussi précisé les conditions de croissance de ces champignons à différentes températures sur milieu artificiel (Lieutier, Yart, 1989). Nous nous proposons maintenant d'apporter des informations sur leur croissance dans les conditions naturelles (rondins de pin sylvestre ou arbre vivant) et sur la cinétique de développement de la réaction résinique qu'ils induisent. $\mathrm{Ce}$ travail n'avait encore jamais été réalisé en ce qui concerne les champignons associés aux scolytides. Le but est de mieux connaître les agresseurs potentiels du pin sylvestre lors des attaques des 2 scolytides considérés, de mieux comprendre le fonctionnement de la réaction de défense induite de l'arbre et d'en déterminer des critères de mesure et des paramètres caractéristiques.

\section{MATÉRIELS ET MÉTHODES}

Tous les champignons ont été obtenus à partir de cultures monospores entretenues au laboratoire sur milieu malt-agar et issues précédemment des insectes et de leurs galeries (Lieutier et al, 1989b). Ce sont Ophiostoma brunneo-ciliatum Math-K et Ophiostoma ips (Rumb) Nannf, provenant d'lps sexdentatus, Lep- tographium wingfieldii Morelet, Ophiostoma minus Hedgc et Hormonema dematioides Lagerb et Melin, provenant de $T$ piniperda. Ces champignons seront dans ce qui suit abrégés respectivement en $O b, O i$, $L w, O m$ et $H d$. Dans toutes les expérimentations concernant une espèce donnée de champignon, la même culture monospore a été utilisée. Dans tous les cas, les implants étaient constitués d'une pastille de malt-agar de $5 \mathrm{~mm}$ de diamètre, découpée à l'emporte-pièce dans une culture sporulée âgée de 2 semaines. Ils ont été appliqués dans le fût des arbres et dans les rondins selon la méthode déjà décrite (Lieutier et al, 1989b) et dérivée de celle de Wright (1933).

\section{Inoculations sur rondins de pin sylvestre}

Trois pins sylvestres dominés de 50 à $60 \mathrm{~cm}$ de circonférence à $1 \mathrm{~m}$ du sol ont été abattus le 30 mai 1988 en forêt d'Orléans. Un rondin de 1,20 m de long issu de la partie basale a été tiré de chacun d'eux et stocké à $5^{\circ} \mathrm{C}$ (rondins $A$ ). Le 3 juin, 3 nouveaux pins sylvestres comparables ont subi le même traitement, mais les rondins n'ont pas été placés en chambre froide (rondins $B$ ). Le 3 juin, tous les rondins ont été inoculés ; les rondins $A$ avaient été sortis de la chambre froide $5 \mathrm{~h}$ avant les inoculations. Chacun des 6 rondins a reçu des inoculations disposées en couronne autour du tronc à raison de 3 couronnes espacées l'une de l'autre de $40 \mathrm{~cm}$, dont chacune comportait 6 implants, 1 de chaque espèce de champignon et 1 de malt-agar seul. Les rondins ont ensuite été paraffinés sur leurs sections afin de limiter les pertes en eau, et placés à $20^{\circ} \mathrm{C}$.

Les lectures ont été faites après 3,10 , puis $30 \mathrm{j}$ de culture, dans un ordre systématique à partir d'une extrémité des rondins, par examen à chaque fois d'une couronne par rondin selon le protocole suivant :

- enlèvement de l'écorce sur toute la surface de la réaction de défense correspondant à ces inoculations ;

- pour chaque inoculation, mensuration de l'extension longitudinale de la réaction résinique de défense du phloème, de chaque côté du point d'inoculation ;

- sur 1 des 2 côtés tiré au hasard, prélèvement stérile tous les $5 \mathrm{~mm}$ à partir du point d'inoculation, d'un fragment de phloème repiqué ensuite sur malt-agar, afin d'y apprécier la présence du champignon inoculé. Dix et 30 j après les inoculations, immédiatement après les prélèvements du phloème correspondants, tous les rondins ont, en outre, été coupés transversalement au niveau de la couronne d'inoculation afin d'apprécier, par examen du bleuissement de l'aubier, la croissance des champignons à l'intérieur de ce tissu. On avait en effet pu constater précédemment que $L w, O m, O i$, et $O b$ étaient tous capables de provoquer le bleuissement (Lieutier et al, 1989b). Après chaque lecture, toutes les surfaces mises à nu ont été paraffinées.

\section{Inoculations sur arbres vivants}

Durant l'hiver 1986-87, 15 pins sylvestres ont été choisis en forêt d'Orléans d'après leur indice de productivité instantanée (GE) appréciée, grâce à 2 carottes de 
sondage diamétralement opposées, par le rapport entre la surface de la section du dernier cerne d'accroissement et la surface de la section d'aubier à 1,30 m (Waring, Pitman, 1980). Neuf de ces pins (arbres F) possédaient un indice GE compris entre $5,5 \%$ et $6,3 \%$ et une circonférence comprise entre $54 \mathrm{~cm}$ et $83 \mathrm{~cm}$ à $1,30 \mathrm{~m}$. Pour les 6 autres pins (arbres f), GE était compris entre 1,3 et $1,7 \%$ et la circonférence à $1,30 \mathrm{~m}$ variait de 53 à $86 \mathrm{~cm}$. Ces arbres ont été inoculés par groupes de 5 ( $3 F$ et $2 f)$ à 3 saisons différentes : le 30 mars 1987 (quelques j après la fin de la période de vol et d'attaque de $T$ piniperda) pour le $1^{\text {er }}$ groupe, le 25 mai 1987 (peu après le vol de la première génération $d^{\prime} l$ sexdentatus) pour le $2^{\mathrm{e}}$ groupe, et le 31 août 1987 (après le vol de la deuxième génération $d^{\prime} /$ sexdentatus) pour le $3^{\theta}$ groupe. Chaque arbre a reçu 6 couronnes d'inoculation espacées les unes des autres de $30 \mathrm{~cm}$, et constituées chacune de 6 implants (1 pour chaque champignon et 1 de malt-agar seul).

Les lectures ont eu lieu 1 j, 3 j, 7 j, 14 j, 30 j, et 60 j après les inoculations. A chacune de ces dates, une couronne a été examinée sur chaque arbre, en retirant la surface d'écorce la plus réduite possible et compatible avec l'examen des réactions de défense dans le phloème, en commençant par les couronnes inférieures. Les examens ont eu lieu selon le protocole suivant :

- mensuration de la longueur totale de la réaction de défense (partie supérieure et partie inférieure) sur la face interne (côté cambium) comme sur la face externe du phloème ;

- prélèvement stérile du quart supérieur gauche de la réaction, dans lequel des isolements ont ensuite été effectués au laboratoire tous les $5 \mathrm{~mm}$ à partir du point d'inoculation, afin d'apprécier jusqu'où le champignon avait pu se développer ;

- prélèvement du quart supérieur droit de la réaction et immersion immédiate dans une solution saturée d'acétate de cuivre de façon à fixer et colorer spécifiquement les sécrétions résiniques (Johansen, 1940 ; Lieutier, Berryman, 1988) ; au laboratoire, des coupes transversales de ce prélèvement ont été effectuées manuellement à la lame de rasoir, puis montées à la glycérine; elles ont eu lieu à $10 \mathrm{~mm}$ et $30 \mathrm{~mm}$ du point d'inoculation, ainsi qu'au niveau de la partie médiane de la réaction, sur une largeur de $5 \mathrm{~mm}$ à partir de l'axe central vertical de la réaction; la proportion de tissu imprégné de résine a ensuite été estimée sur ces sections ;

- prélèvement des deux quarts inférieurs de la réaction ; placés immédiatement sous atmosphère d'azote et dans la glace carbonique, ces prélèvements ont été ensuite stockés au laboratoire à $-35^{\circ} \mathrm{C}$ jusqu'au dosage de la résine ; celui-ci a été effectué sur l'un des 2 quarts inférieurs, d'une part sur un échantillon correspondant aux $20 \mathrm{~mm}$ les plus proches du point d'inoculation dans le sens longitudinal et ayant une largeur de $5 \mathrm{~mm}$ à partir de l'axe central de la réaction, d'autre part sur le reste du quart de réaction ; ceci a permis de connaître d'une part la concentration en résine dans les 20 premiers $\mathrm{mm}$ les plus proches du point d'inoculation, d'autre part et après regroupement des 2 dosages, la quantité totale de résine synthétisée dans la réaction ;

- prélèvement d'un échantillon de phloème issu d'y zone non inoculée et soumis aux mêmes traitements que les 2 quarts inférieurs des réactions; sa teneur en résine a été mesurée afin de n'obtenir, par soustraction aux dosages précédents, que les teneurs en résine induite. L'extraction dans le pentane et les dosages par pesées après évaporation du solvant ont été effectués selon la méthode déjà décrite (Lieutier et al, $1989 b)$ et inspirée en partie de celle de Christiansen (1985).

Au $60^{\circ} \mathrm{j}$, les arbres ont été abattus et sectionnés transversalement au niveau de la couronne d'inoculation examinée ce jour-là. L'extension en profondeur de la réaction résinique dans l'aubier a été notée au niveau de chaque inoculation. Une rondelle de bois a été prélevée et ramenée au laboratoire où des isolements ont été effectués tous les 2 à $3 \mathrm{~mm}$ en profondeur à partir de chaque point d'inoculation, afin d'apprécier l'extension du champignon dans l'aubier.

Dans tous les résultats, les intervalles de confiance ont été calculés au seuil de $95 \%$.

\section{RÉSULTATS}

\section{Inoculations sur rondins}

Aucune différence notable entre les 2 traitements n'ayant pu être constatée, les résultats sont présentés et sont analysés ensemble pour les 6 rondins.

Dans le phloème (fig 1), la zone d'extension des champignons est toujours inférieure à celle de la réaction du moins quand ces zones n'ont pas des dimensions très petites. Pour tous les champignons après $3 \mathrm{j}$, et surtout pour $L w$ et Om à $10 \mathrm{j}$ et $30 \mathrm{j}$, cette zone de réaction apparaît translucide et allongée longitudinalement et se présente sous le même aspect que chez les arbres vivants ; la quantité de résine y est cependant extrêmement faible et l'on n'observe jamais d'écoulements. Dans les autres cas, on n'observe qu'une zone brunâtre présentant l'aspect d'une nécrose, mais dans la partie terminale de laquelle on n'a jamais pu isoler de champignons. Tous les champignons semblent capables d'induire cette réaction, mais à des degrés divers. Les réactions les plus étendues sont associées à $O m$ et $L w$ qui présentent également la croissance la plus importante. $O i$ et $O b$ induisent des réactions de taille moyenne, bien que leur croissance reste modeste. $\mathrm{Hd}$ a une très faible croissance et n'induit qu'une faible réaction, comparable à celle du témoin.

Dans l'aubier (fig 2), seules les inoculations de $O i, O b$ et $O m$ ont donné lieu à un bleuissement dont l'extension était notable, celui associé à Om apparaissant le plus important. A l'exception d'un seul cas, les inoculations de $L w$ n'ont jamais fourni de bleuissement. Celles de Hd ont fourni des bleuissements dont l'extension était extrêmement réduite. 


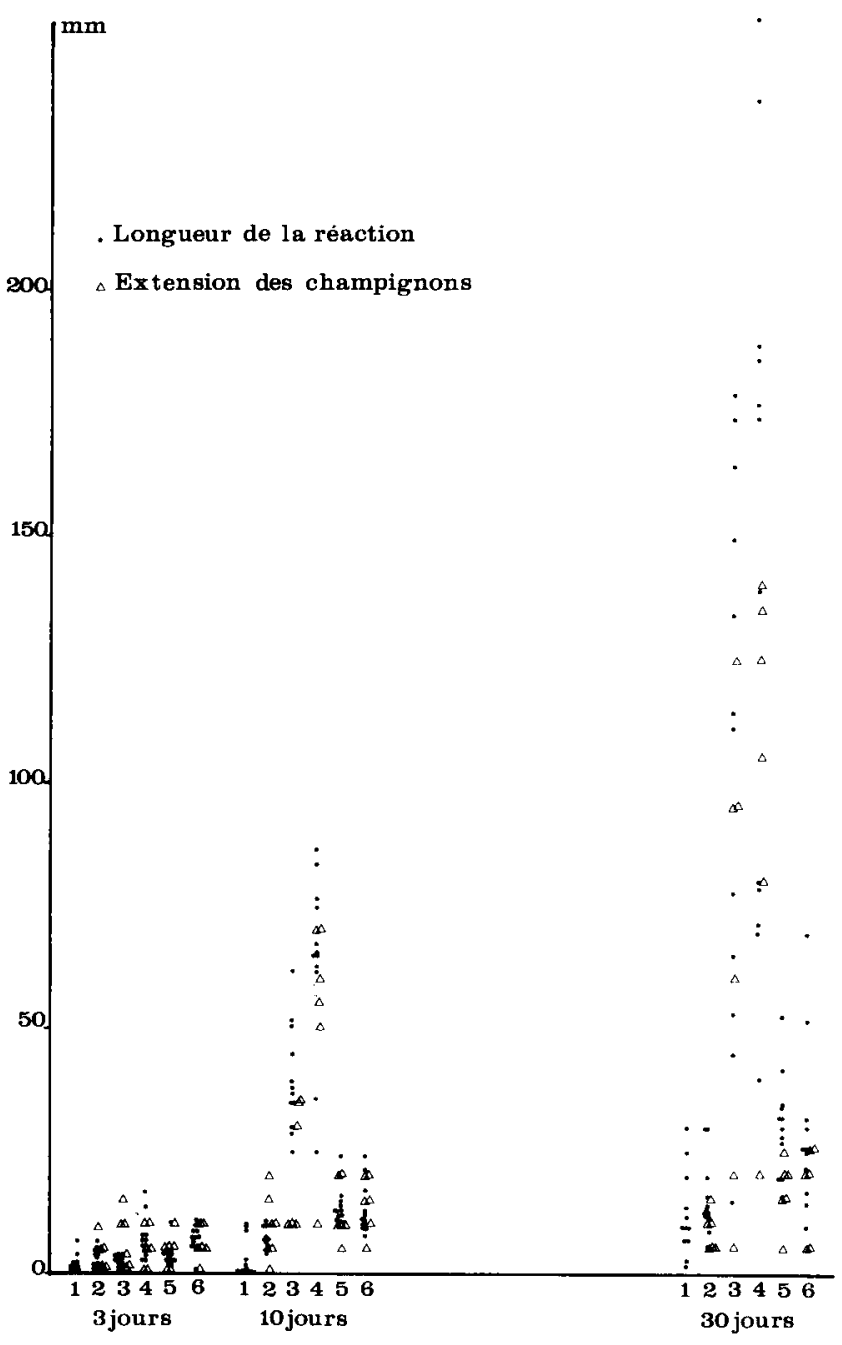

Fig 1. Croissance des champignons et longueur de la réaction de défense (mesurées sur une moitié de réaction dans le sens longitudinal) dans le phloème des rondins de pin sylvestre. 1 = cas d'une inoculation témoin ; $2=$ cas d'une inoculation d'Hormonema dematioides; $3=$ cas d'une inoculation d'Ophiostoma minus ; 4 = cas d'une inoculation de Leptographium wingfieldii; $5=$ cas d'une inoculation d'Ophiostoma brunneo-ciliatum; 6 = cas d'une inoculation d'Ophiostoma ips.

\section{Inoculations sur arbres vivants}

Nous n'avons pu établir aucune différence entre les arbres $F$ et $f$, ni pour la croissance des champignons ni pour les réactions de défense, quelles qu'aient été les méthodes d'appréciation. Les résultats sont donc présentés dans ce qui suit pour les 5 arbres groupés, à chaque saison. L'amplitude des intervalles de confiance est telle que les différences discutées ne sont pas toujours significatives, mais la répétitivité des résultats et leur concordance dans les diverses expérimentations laissent penser que les différences observées correspondent malgré tout à des faits réels.

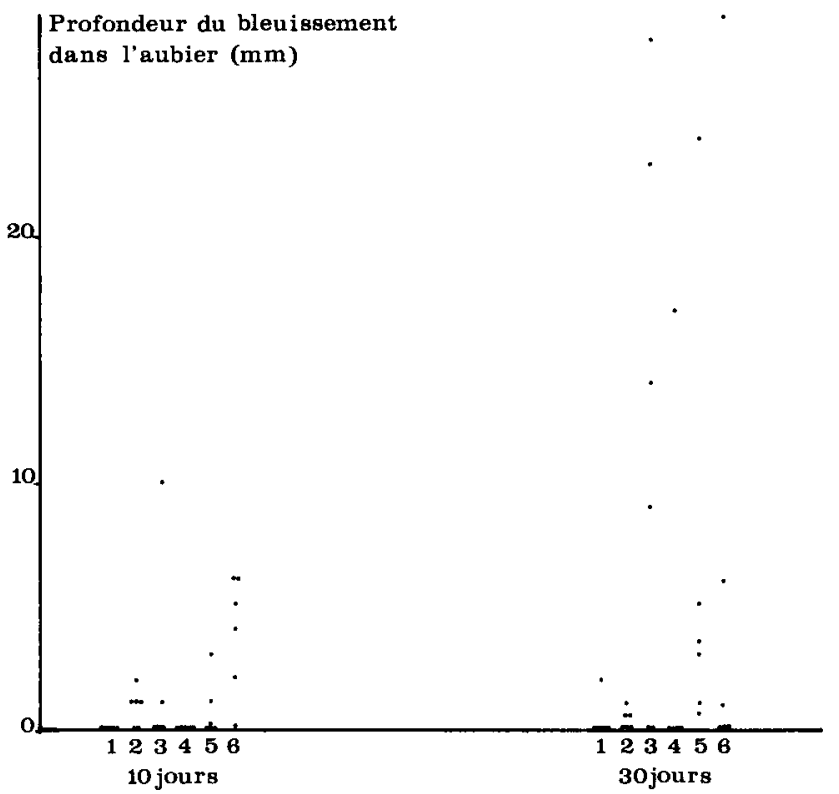

Fig 2. Extension en profondeur du bleuissement de l'aubier des rondins de pin sylvestre. Chaque point de la figure correspond à un rondin. $1,2,3,4,5,6=$ même signification que fig 1.

\section{Extension de la réaction résinique dans le phloème}

Pour toutes les inoculations, 2 zones réactionnelles translucides très allongées dans le sens longitudinal ont pu être distinguées. L'une correspond au phloème proprement dit et est lisible sur la face externe de ce tissu (côté écorce); l'autre est lisible sur la face interne des prélèvements et correspond à une réaction dans le cambium. Jusqu'à 7 ou $14 j$ après les inoculations, la réaction cambiale, qui présente toutefois une très grande variabilité, s'avère plus étendue que la réaction du phloème ; après ce délai, les 2 réactions ont une longueur semblable et il n'est plus possible de les distinguer.

Dans le phloème (fig $3 a, b, c$ ), toutes les réactions croissent jusqu'à un plateau dont le niveau et la date d'apparition varient selon la saison et les champignons. Le temps de latence avant réaction varie aussi. Ce délai est le plus court en $3^{\theta}$ saison, le plus long en $1^{\text {re }}$ saison. Le plateau est aussi atteint plus tôt en $3^{\theta}$ saison. Cependant, c'est en $2^{e}$ saison que les niveaux sont finalement les plus élevés. Dans tous les cas, $L w$ induit les réactions les plus grandes, les plus intenses et les plus précoces, suivi par $\mathrm{Om}$. $H d$ provoque des réactions comparables à celles des témoins; $O i$ et $O b$ sont intermédiaires.

\section{Croissance des champignons dans le phloème (fig $3 \mathrm{~d}, \mathrm{e}, \mathrm{f}$ )}

Quelle que soit l'espèce inoculée, la zone d'extension des champignons est toujours inférieure 

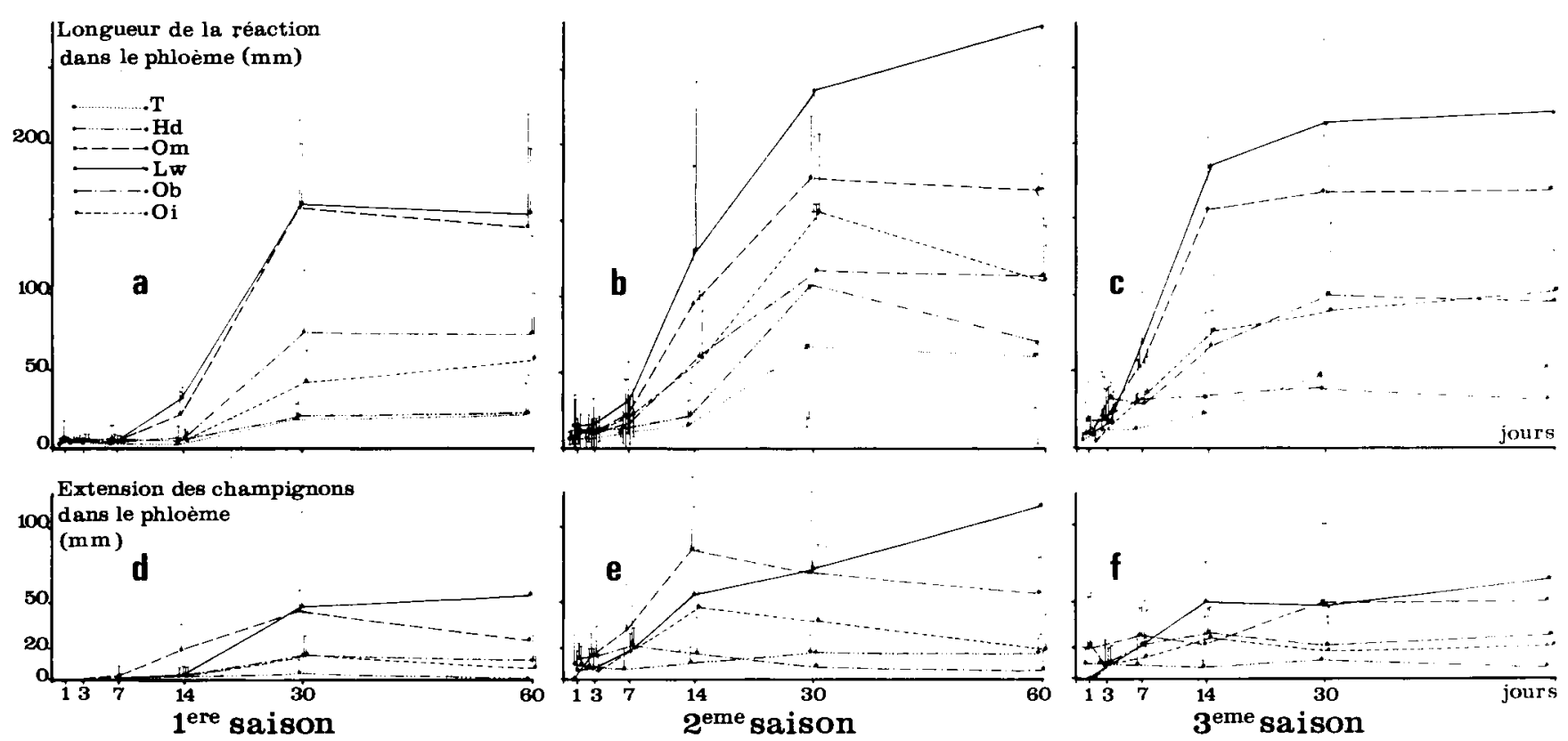

Fig 3. Évolution de la longueur totale (mesurée dans le sens longitudinal) de la réaction de défense (a, b, $c$ ) et de la zone d'extension des champignons $(\mathrm{d}, \mathrm{e}, \mathrm{f})$ dans le phloème des pins sylvestres vivants. $T=$ cas d'une inoculation témoin ; $H d=$ cas d'une inoculation par Hormonema dematioides ; $O m=$ cas d'une inoculation par Ophiostoma minus ; $L w=$ cas d'une inoucluation par $L$ eptographium wingfieldii; $O b=$ cas d'une inoculation par Ophiostoma brunneo-ciliatum; $O i=$ cas d'une inoculation par Ophiostoma ips. Les barres verticales représentent les intervalles de confiance au seuil de $95 \%$.

à celle de la réaction résinique. C'est à la $2^{\mathrm{e}}$ saison que leur croissance est la plus importante. Elle est de même ordre pour la $1^{\text {re }}$ et la $3^{e}$ saison ; pourtant, le démarrage de la croissance est très rapide en $3^{e}$ saison et très long en $1^{r e}$ saison. Après une période de croissance plus ou moins linéaire, tous les champignons finissent par atteindre une extension maximale au $30^{\mathrm{e}} \mathrm{j}$ pour la $1^{\text {re }}$ saison, plus précocement pour les $2^{\mathrm{e}}$ et $3^{\theta}$ saisons. $L w$ fait toutefois exception puisque, à la $2^{\ominus}$ saison, sa croissance semble encore se poursuivre après $30 \mathrm{j}$.

$L w$ et $O m$ ont toujours une croissance très supérieure à celle des autres champignons, ce phénomène étant particulièrement net à la $1^{\text {re }}$ saison. Om croît toujours très précocement mais il se stabilise rapidement. En revanche $L w$, plus lent à démarrer et comparable au départ à Oi et à $O b$, s'étend finalement plus loin que $O m ; H d$ ne s'étend jamais très loin ; $O i$ et $O b$ sont intermédiaires.

\section{Évolution des teneurs en résine dans la réaction du phloème}

Dans les 20 premiers $\mathrm{mm}$ de la réaction (fig 4), aucune accumulation de résine n'est notée dans les $7 \mathrm{j}$ qui suivent les inoculations à la $1^{\text {re }}$ saison, alors que l'accumulation est immédiate aux $2^{\mathrm{e}}$ et $3^{e}$ saisons. La concentration résinique dans cette zone augmente ensuite plus ou moins rapidement, de façon non linéaire et atteint générale- ment un plateau dont le niveau varie selon la saison et les champignons, sauf pour $O i$ et $O b$ en $1^{\text {re }}$ saison. L'accumulation est rapide et importante aux $2^{\theta}$ et $3^{\theta}$ saisons, lente et relativement faible en $1^{\text {re }}$ saison. Elle est aussi la plus rapide et la plus importante pour $O m$ et $L w$, à l'opposé de $H d$ et des inoculations témoins, $O i$ et $O b$ occupant des positions intermédiaires.

La quantité totale de résine présente dans l'ensemble de la réaction (fig 5) augmente très lentement et jusqu'à de faibles valeurs en $1^{\text {re }}$ saison, très rapidement et jusqu'à des valeurs plus fortes en $3^{\mathrm{e}}$ et surtout en $2^{\mathrm{e}}$ saisons. Cette accumulation semble linéaire tant qu'un plateau n'est pas atteint. $H d$ et les inoculations témoins induisent les sécrétions les moins importantes, Om et $L w$ les plus importantes. Cependant, alors qu'elle est comparable à celle mesurée pour $O m$ en $1^{\text {re }}$ saison, la quantité totale de résine synthétisée pour $L w$ atteint en $2^{e}$ et $3^{e}$ saisons des valeurs considérables et nettement supérieures à celles induites par $\mathrm{Om}$.

\section{Évolution de la réaction résinique du phloè- me appréciée par coupes histologiques}

Pour les 2 premières saisons, les coupes histologiques effectuées en bordure de la réaction au $60^{\mathrm{e}} \mathrm{j}$ après les inoculations montrent nettement la présence d'un bourrelet cicatriciel en périphérie de toutes les inoculations. Ce bourrelet est totalement absent au $30^{\mathrm{e}} \mathrm{j}$. Pour la $3^{\mathrm{e}}$ saison, la formation du bourrelet a déjà débuté au $30^{\mathrm{e}} \mathrm{j}$. 

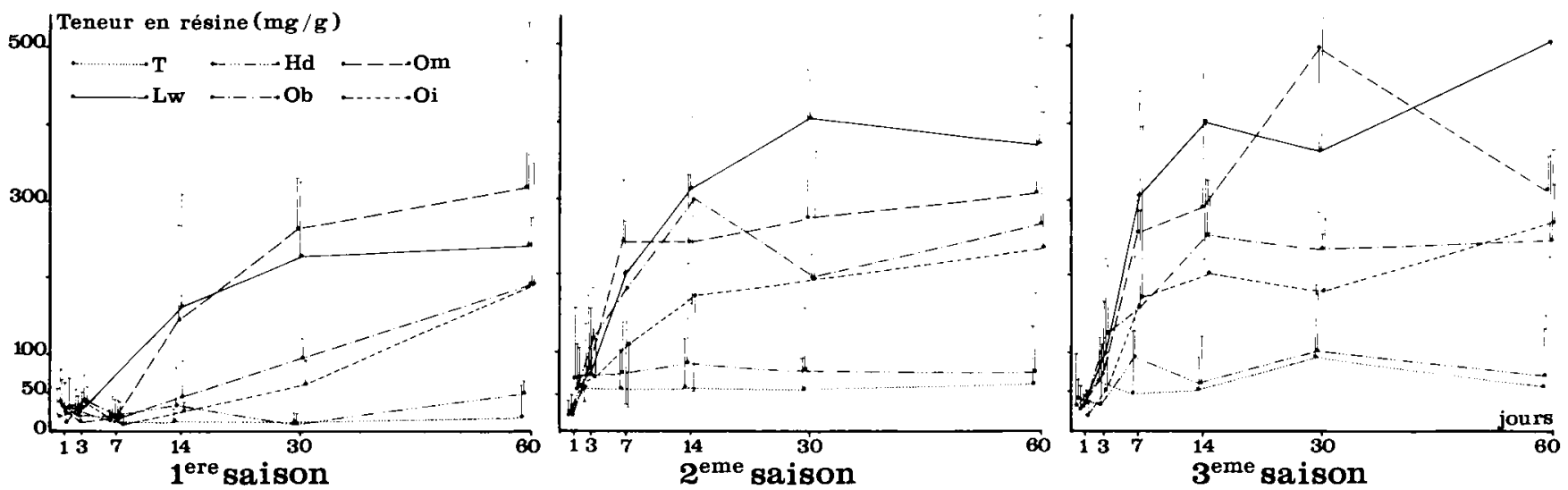

Fig 4. Evolution de la teneur en résine dans les 20 premiers millimètres de la réaction de défense du phloème des pins sylvestres vivants. $T, H d, O m, L w, O b, O i=$ même signification que dans la fig 3 . Les barres verticales représentent les intervalles de confiance au seuil de $95 \%$.
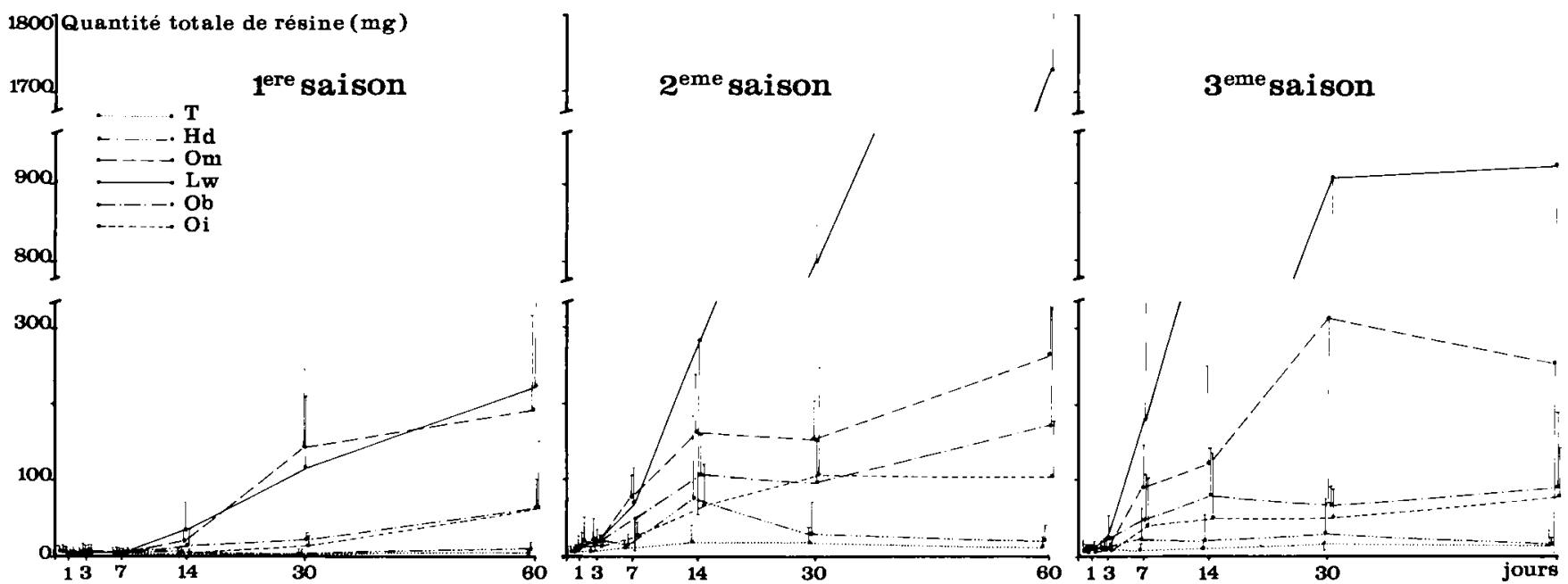

Fig 5. Evolution de la quantité totale de résine présente dans la réaction de défense du phloème des pins sylvestres vivants (valeurs pour $1 / 4$ de la réaction de défense). $T, H d, O m, L w, O b, O i=$ même signification que dans la fig 3 . Les barres verticales représentent les intervalles de confiance au seuil de $95 \%$.

La présence de résine de réaction dans les tubes criblés du phloème, à $10 \mathrm{~mm}$ du point d'inoculation (fig $6 a, b, c)$ ne commence à être visible qu'après le $7^{\theta} \mathrm{j}$ pour la $1^{\text {re }}$ saison, alors qu'elle l'est dès le $1^{\text {er }}$ ou le $3^{\circ} \mathrm{j}$ pour les autres saisons. Le pourcentage de cellules contenant de la résine à ce niveau augmente ensuite plus ou moins rapidement selon la saison et les champignons, pour tendre à atteindre la totalité du tissu. $H d$ et les inoculations témoins ne provoquent toutefois qu'un très faible pourcentage d'imprégnation résinique, toujours inférieur à $20 \%$. Les autres champignons peuvent induire une imprégnation totale du tissu, toujours plus précocement pour $O m$ et $L w$ que pour $O i$ et $O b$.

A $30 \mathrm{~mm}$ du point d'inoculation, les courbes présentent la même allure que celles obtenues à $10 \mathrm{~mm}$, avec un décalage dans le temps dû à la distance. Ainsi, la résine n'apparaît dans les tubes criblés, à $30 \mathrm{~mm}$ du point d'inoculation, qu'après le $14^{\mathrm{e}} \mathrm{j}$ en $1^{\mathrm{re}}$ saison, le $7^{\mathrm{e}}$, en $2^{\mathrm{e}}$ saison et le $3^{\mathrm{a}}$, en $3^{\mathrm{a}}$ saison. A cette distance, même après $60 \mathrm{j}$, les tubes criblés ne sont pas tous concernés. Les pourcentages ne dépassent généralement pas 50 à $70 \%$; ainsi en est-il des réponses à $O m$ et $L w$ en $1^{\text {re }}$ saison (où pendant ce temps les réponses à $O i$ et $O b$ sont inférieures à $20 \%$ ), des réponses à $O m, L w, O i$ et $O b$ en $2^{e}$ saison, et des réponses à $O b$ en $3^{\circ}$ saison (où la réponse à Oi n'atteint que $40 \%$ ). Seules les réponses à $O m$ et $L w$ en $3^{\theta}$ saison atteignent 80 à $90 \%$, mais présentent malgré cela un plateau. Les réponses à $H d$ et à l'inoculation témoin concernent toujours, à $30 \mathrm{~mm}$, un pourcentage inférieur à $5 \%$.

Au niveau de la partie médiane de la réaction (fig $6 \mathrm{~d}, \mathrm{e}, \mathrm{f}$ ), dont la localisation évolue bien sûr avec la croissance en longueur de celle-ci, l'imprégnation des cellules débute après le $7^{\ominus}$ j en $1^{\text {re }}$ saison, dès le $1^{\text {er }}$ ou le $3^{e} \mathrm{j}$ en $2^{\theta}$ ou $3^{\theta}$ saison. Le pourcentage de cellules concernées augmente ensuite rapidement. Une stabilisation et même parfois une diminution de ce pourcentage intervient cependant fréquemment à partir du $7^{\ominus}$ ou du $14^{\mathrm{e}} \mathrm{j}$, sa croissance ne reprenant qu'à partir du $30^{\theta} \mathrm{j}$ (ou du $14^{\theta}$ pour certaines réactions en $3^{\ominus}$ 

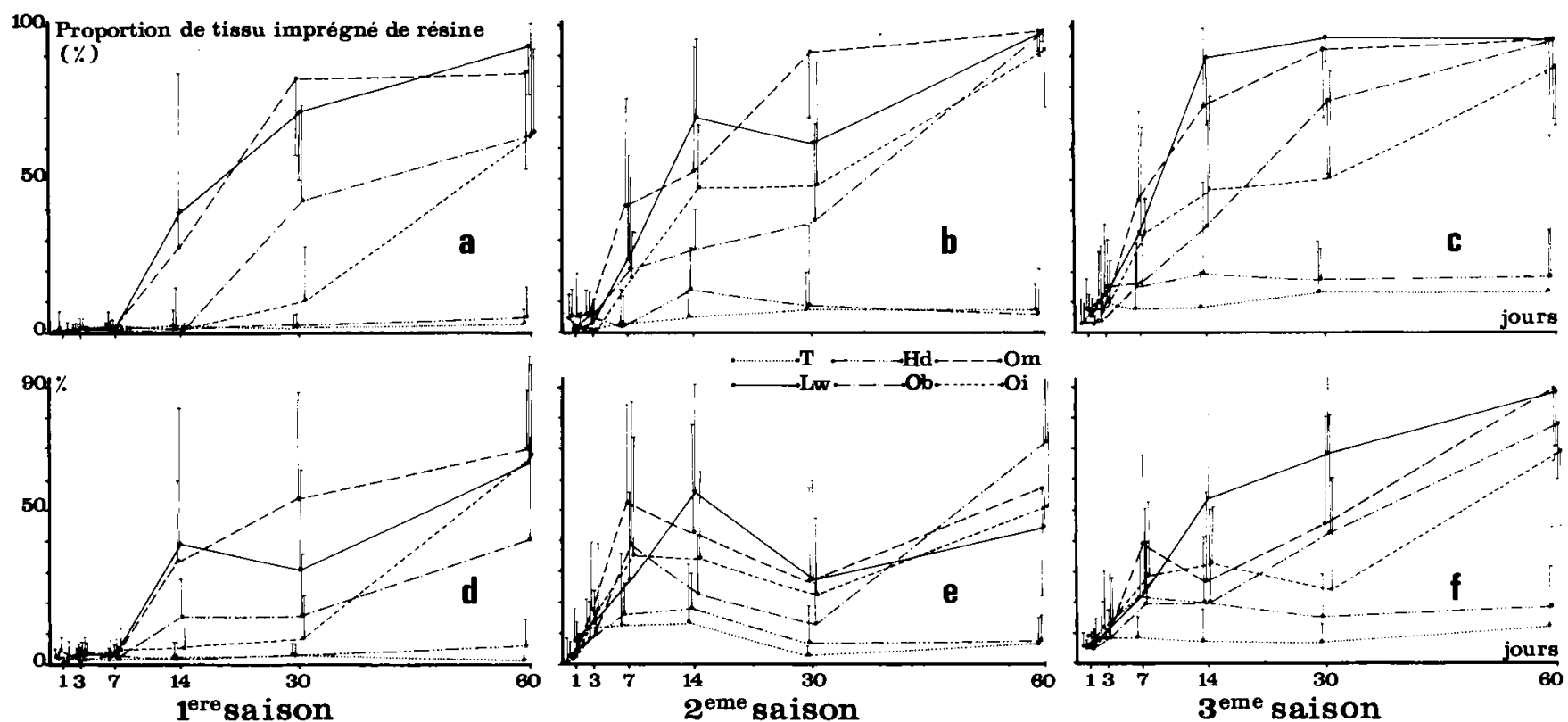

Flg 6. Evolution de la proportion de tissu imprégné de résine sur des sections transversales du phloème réactionnel des pins sylvestres vivants. Les sections sont localisées à $10 \mathrm{~mm}$ du point d'inoculation $(a, b, c)$ ou au niveau de la zone médiane de la réaction (d, e, f) dans le sens longitudinal. $T, H d, O m, L w, O b, O i=$ même signification que dans la fig 3 . Les barres verticales représentent les intervalles de confiance au seuil de $95 \%$.

saison). Ce phénomène concerne toutes les réactions en $2^{\theta}$ saison, mais celles dirigées contre $O m$ en $1^{\text {re }}$ saison et contre $L w$ en $3^{e}$ saison semblent y échapper.

\section{Croissance des champignons et extension de la réaction de défense dans la profondeur de l'aubier (fig 7)}

Comme dans le phloème, la zone d'extension de tous les champignons est incluse dans celle de la réaction résinique qu'ils provoquent. Aux 2 premières saisons, $L w$ et $O m$ induisent les réactions les plus importantes. Les réactions dirigées contre $\mathrm{Oi}$ et $\mathrm{Ob}$ ont la même dimension en toutes saisons; en $3^{\theta}$ saison, elles sont comparables à celles dirigées contre $L w$ et $O m$. $H d$ provoque toujours des réactions très faibles et a toujours une croissance très réduite. Om s'étend assez profondément dans l'aubier en $1^{\text {re }}$ et surtout en $2^{\theta}$ saison. $L w$ ne pousse correctement dans l'aubier qu'en $1^{\text {re }}$ saison. Oi et $O b$ réussissent à pousser quelque peu dans l'aubier en $1^{\text {ro }}$ et en $2^{\theta}$ saison, mais ne s'étendent pas à une profondeur importante. Aucun champignon ne réussit réellement à pénétrer dans l'aubier en $3^{\mathrm{e}}$ saison.

\section{DISCUSSION}

L'absence de différence entre les 2 groupes de rondins (frais ou âgés de 4 j) semble pouvoir s'expliquer par la méthode de vieillissement des rondins, la conservation en chambre froide pen-

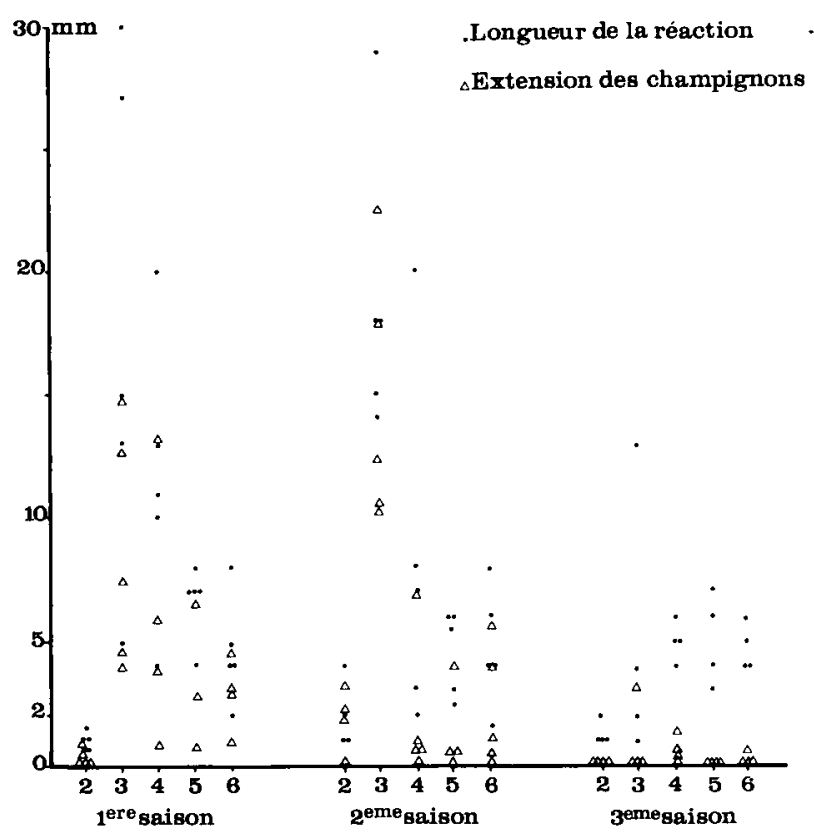

Fig 7. Extension en profondeur des champignons et de la réaction de défense dans l'aubier des arbres vivants 60 jours après les inoculations. Chaque point de la figure correspond à un rondin. $2,3,4,5,6=$ même signification que dans la fig 1.

dant $4 \mathrm{j}$ ayant sans doute préservé les caractéristiques initiales des rondins frais. S'il n'est donc pas possible de déduire de cette expérience certaines exigences éventuelles des champignons quant à la fraîcheur de leur substrat, du moins peut-on en tirer une conclusion pratique pour des expérimentations futures sur rondins.

Pour les 2 lots ( $F$ et $f$ ) d'arbres vivants, l'absence de différence peut sembler étrange puis- 
qu'il a été montré que l'importance des réactions de défense du pin sylvestre (dans le cas d'inoculations peu nombreuses) était liée à sa productivité instantanée (Lieutier, Ferrell, 1988). Toutefois, cette liaison est statistique et il existe une certaine dispersion des valeurs de la réaction (longueur et concentration en résine) pour une productivité donnée. Pour espérer obtenir des différences notoires entre les groupes $f$ et $F$ dans notre expérimentation, il nous aurait donc probablement fallu prendre un nombre plus élevé d'arbres dans chacun des 2 groupes et choisir des indices de productivité plus éloignés l'un de l'autre.

La discussion qui suit sera donc menée en considérant que les 5 arbres vivants constituent 5 répétitions de la même expérience, de même que les 6 rondins constitueront 6 répétitions de l'expérience les concernant.

\section{Agressivité et rôle des champignons}

Que l'on considère la vitesse de croissance des champignons, la brièveté des délais de réponse de l'arbre, la rapidité d'atteinte des maxima de cette réponse ou ses niveaux, dans tous les cas et pour tous les critères mesurés, $L w$ arrive en tête, suivi de $\mathrm{Om}$. Hd se comporte comme un saprophyte en induisant des réactions comparables à celles des inoculations témoins. $O i$ et $O b$ sont intermédiaires. Ce classement confirme nos précédents résultats et permet de caractériser chaque champignon par son agressivité relative pour le pin sylvestre (Lieutier et al, 1989b).

Les différences de croissance entre champignons et selon la saison ne peuvent s'expliquer uniquement par les preferenda thermiques et par l'existence des réactions de défense.

Bien que les exigences ou preferenda thermiques (Lieutier et Yart, 1989) puissent expliquer les différences de croissance des champignons dans l'aubier entre la $1^{\text {re }}$ saison (avril-mai) et la $2^{e}$ saison (juin-juillet), l'explication doit être autre en $3^{\theta}$ saison (septembre-octobre), où aucun champignon ne se développe dans l'aubier alors que la température est encore propice. De même, la croissance des champignons dans le phloème ne reflète pas toujours leur preferendum. Ainsi $L w$, dont l'optimum est plus bas que celui des autres champignons (Lieutier, Yart, 1989) pousse mieux dans l'aubier en $1^{\text {re }}$ qu'en $2^{\mathrm{e}}$ saison, mais manifeste dans le phloème le phénomène inverse. Si donc la température peut contribuer à expliquer les différences entre champignons, selon la saison, elle n'est certainement pas le seul facteur en cause.
On attribue en général aux réactions de défense un rôle néfaste au développement des champignons inoculés par les Scolytides (Berryman, 1972 ; Raffa, Berryman, 1983; Christiansen et al, 1987). Ces réactions sont susceptibles de varier en fonction du niveau et de la disponibilité des réserves (Lorio, Hodges, 1985 ; Christiansen et al, 1987) et donc aussi sans doute en fonction de la saison. Elles pourraient donc constituer un facteur explicatif des différences ici observées.

Remarquons déjà que certains champignons poussent plus ou moins bien selon la nature du substrat, phloème ou aubier (figs 1 et 2); or ces variations sont les mêmes qu'il s'agisse des inoculations sur rondins ou sur arbre vivant. En outre, malgré de fortes réactions en $2^{e}$ saison, tous les champignons réussissent à cette période à pousser dans le phloème et dans l'aubier, beaucoup mieux qu'en $3^{\mathrm{e}}$ saison et en $1^{\mathrm{re}}$ saison. Par ailleurs, sur arbre vivant, tous les champignons ont en $1^{\text {re }}$ saison une croissance, soit comparable (cas du phloème), soit supérieure (cas de l'aubier) à celle qu'ils ont en $3^{\circ}$ saison, ce qui ne peut, nous l'avons vu, s'expliquer par la température. Les fortes réactions de défense en $3^{e}$ saison pourraient expliquer ces différences saisonnières dans l'aubier, mais non dans le phloème. D'autre part, le classement des champignons selon leur vitesse de croissance reste identique, que le test ait lieu sur rondin (réactions faibles et sans succès) ou sur arbre vivant (réactions fortes et victorieuses), où même sur maltagar où la réaction est nulle (Lieutier, Yart, 1989). Les différences de vitesse de croissance de ces micro-organismes et leur aptitude relative à mieux pousser dans le phloème ou l'aubier ne sont donc pas liées à l'existence des réactions de défense, ou à des différences de tolérance à la résine.

En ce qui concerne les différences entre champignons, les facteurs supplémentaires en cause doivent sans doute être recherchés dans les caractéristiques intrinsèques de ces microorganismes. Dans le cas des différences en fonction de la saison, il faut certainement y ajouter des facteurs liés à l'état physiologique de l'arbre, en dehors même de ceux qui conditionnent les capacités de défense. Cela n'exclut pas bien sûr que les réactions de défense jouent un rôle pour stopper les champignons.

Les différences dans leur croissance et dans les réactions qu'ils provoquent peuvent suggérer, pour certains champignons, un rôle possible dans les mécanismes d'installation des insectes et la mort des arbres attaqués.

Par un meilleur développement dans le phloème des arbres vivants tant en $1^{r \theta}$ qu'en $2^{e}$ et $3^{e}$ saisons, par son agressivité élevée, et par ses 
préférences pour les températures moyennes ou peu élevées et sa très bonne croissance à $5{ }^{\circ} \mathrm{C}$ (Lieutier, Yart, 1989), Lw paraîtrait le mieux placé, parmi les champignons isolés de $T$ piniperda, pour jouer un rôle sur l'arbre dans une association réelle avec cet insecte, malgré une fréquence d'association ne dépassant que rarement 13\% (Lieutier et al, 1989 b). Toutefois, s'il est capable de réaliser une croissance importante dans le phloème, il reste toujours très en arrière du front de développement de la réaction qu'il induit. Sa croissance dans le phloème est relativement lente au départ. En outre, il ne pousse pas de façon excellente dans l'aubier, en tout cas moins bien que $\mathrm{Om}$. II est donc peu probable que Lw puisse jouer un rôle direct dans la mort des arbres attaqués par $T$ piniperda, du moins par une obstruction mécanique des trachéides. En revanche, la réaction vive et prolongée qu'il induit dans le phloème le place dans une situation favorable pour jouer un rôle important dans l'épuisement des capacités de défense de l'arbre et donc dans les mécanismes d'installation de la population d'insectes. II reste à déterminer si cette agressivité très élevée est suffisante pour compenser sa faible fréquence d'association avec l'insecte-hôte, d'autant plus qu'une quantité minimale de spores semble nécessaire pour déclencher la réaction de l'arbre (Lieutier et al, 1989a).

Om montre, dès le départ, une croissance très rapide dans le phloème et pousse très bien dans l'aubier, ce qui pourrait le rendre capable de tuer des arbres dans certaines conditions (arbres affaiblis par exemple). Sa nocivité pour diverses espèces de pins a d'ailleurs déjà été démontrée en Amérique du Nord et il a été aussi soupçonné de jouer un rôle dans certains dépérissements de pins sylvestres en France (Piou, Lieutier, 1989 et références incluses). Toutefois et malgré sa dissémination possible par $T$ piniperda, il paraît peu probable que ce rôle soit normalement associé aux attaques de ce scolyte. Son optimum de croissance, tant dans l'aubier que dans le phloème, se situe en effet en $2^{\theta}$ saison alors que les attaques de $T$ piniperda ont lieu généralement avant le mois d'avril; son association avec cet insecte est en outre très irrégulière ( 0 à $46 \%$ ) (Lieutier et al, 1989b). Cela rend aussi très hypothétique son rôle éventuel dans les mécanismes d'installation des populations de $T$ piniperda, malgré une agressivité élevée.

$O i$ et $O b$ ont un développement limité dans l'aubier des arbres vivants, ce qui rend peu probable qu'ils soient les seuls responsables de la mort des arbres attaqués par I sexdentatus. Les réactions qu'ils induisent n'atteignent pas l'ampleur absolue de celles dues aux 2 champignons précédents. Néanmoins, l'accumulation très rapide de résine dans les 20 premiers $\mathrm{mm}$ de la réaction aux $2^{\theta}$ et $3^{\theta}$ saisons, périodes de vol $d^{\prime} /$ sexdentatus, laisse penser que Oi et $O b$ sont susceptibles de jouer un rôle dans les mécanismes d'installation des populations de ce scolytide.

\section{Rôle de la réaction de défense}

Nous nous limiterons à la réaction située dans le phloème, pour laquelle nous possédons une cinétique complète.

La réaction de défense se manifeste tant sur les rondins que sur les arbres vivants. Toutefois son extension et son intensité sont beaucoup plus restreintes dans le premier cas. Sur rondins, la quantité totale de résine est très faible dans la réaction, et le front de réaction devance le front de développement du champignon d'à peine quelques $\mathrm{cm}$. En revanche, sur arbre vivant, la longueur de la réaction atteint jusqu'à 3 fois la longueur de la zone de développement des champignons, et sa teneur en résine est extrêmement élevée. Le développement considérable de la réaction de défense sur arbre vivant, par rapport aux rondins, même très frais, prouve qu'il ne s'agit pas d'une réaction passive, mais au contraire d'un phénomène dynamique dont le plein développement met en jeu les fonctions vitales de la plante et implique l'intégrité du végétal.

En outre, quelle que soit la saison, et pour tous les champignons, la croissance sur arbre vivant est toujours très inférieure à celle sur rondins, même lorsque les conditions sur le terrain sont proches de celles du laboratoire $\left(2^{\theta}\right.$ saison ; comparer sur ce point les figures 1 et $3 e$ ). II est logique alors d'attribuer aux réactions de défense la responsabilité des différences observées entre ces 2 types de milieu. Des tests biologiques sont évidemment nécessaires pour déterminer le rôle exact de cette réaction et des composés qu'elle renferme, mais il est très probable qu'elle exerce au moins une action limitative sur le développement des champignons. L'arrêt, ou du moins le fort ralentissement de la croissance de ces micro-organismes sur arbre vivant, (plateau de leur courbe de croissance) ne peut être dû à la formation du bourrelet cicatriciel. En effet, d'une part les champignons sont encore loin des limites de la réaction au moment de leur arrêt de croissance, d'autre part la formation du bourrelet est toujours postérieure à cet arrêt. On peut penser en revanche que le fort ralentissement de la croissance fongique, suivi du ralentissement de l'extension de la réaction, laisse au bourrelet le 
temps de se former pour endiguer définitivement l'agresseur.

Si la réaction résinique est responsable de l'arrêt de la croissance des champignons, un lien doit exister entre la quantité de résine et la localisation du front du champignon au moment de l'arrêt, à moins qu'il n'y ait "gaspillage" de la part de l'arbre. On peut ainsi tenter de comparer à différentes saisons les quantités de résine présentes dans la réaction ou les concentrations locales au point d'arrêt et à la date d'arrêt. La concentration de résine n'étant connue par dosage chimique que dans les 20 premiers $\mathrm{mm}$ de la réaction, nous lui avons préféré pour ce propos l'examen de la proportion de tissu imprégné de résine sur les coupes histologiques localisées à 10 ou $30 \mathrm{~mm}$ du point d'inoculation, en choisissant à chaque fois celles situées le plus près du point d'arrêt (tableau I). Aucun lien n'apparaît entre la quantité totale de résine sécrétée et la localisation du front de croissance au moment où celle-ci est arrêtée, mais il semble que $O i$ et $O b$ soient stoppés quand 10 à $40 \%$ de la section du phloème est occupé par la résine, tandis que $L w$ et $O m$ seraient stoppés par des taux de l'ordre de 40 à $70 \%$.

\section{Le fonctionnement de la réaction de défense dans le phloème}

Même si elle est faible et totalement inefficace, la réaction de défense se manifeste encore dans les rondins après 30 jours, ce qui suggère que de faibles capacités de synthèse des résines persistent à partir des réserves locales.

Chez les arbres vivants, les capacités locales de synthèse jouent sans doute aussi, mais elles doivent être stimulées, en même temps que des réserves localisées à distance doivent être sollici- tées. Miller et Berryman (1986) ont en effet à ce sujet montré chez Pinus contorta Dougl var latifolia Engelm que l'importance des réactions de défense diminuait quand le phloème des zones inoculées était isolé du reste de l'arbre par des scarifications. L'arbre vivant doit par ailleurs jouer un rôle actif dans le transport de l'éliciteur, quelle que soit son origine, puisque les réactions s'y étendent plus loin en avant du champignon que dans le cas des rondins. Une hypothèse selon laquelle les quantités d'éliciteur sécrétées sont plus importantes chez les arbres vivants que chez les rondins, surtout si ces substances ont leur origine dans l'arbre lui-même, pourrait constituer une autre explication de cette différence.

Puisque la réaction résinique est induite par les champignons, il n'est pas étonnant que dans la plupart des cas, les réactions les plus étendues correspondent aux situations dans lesquelles les champignons sont les plus développés. II existe toutefois quelques exceptions. Ainsi, alors que la croissance des champignons est très réduite en $3^{\theta}$ saison, par rapport à la $2^{\theta}$ saison et y est comparable à celle notée en $1^{r \theta}$ saison, les réactions de défense y sont encore très étendues, seulement légèrement inférieures à ce qu'elles sont en $2^{\theta}$ saison, et en tout cas beaucoup plus développées qu'en $1^{\text {re }}$ saison. Si la température pourrait dans certains cas expliquer les différences observées dans la croissance des champignons, ce n'est pas le cas de l'extension de la réaction. II semble que le pouvoir éliciteur de ces micro-organismes soit stimulé en $3^{\theta}$ saison ou alors que ces éliciteurs puissent être transportés ou diffusés dans le phloème plus facilement à cette époque qu'en $2^{a}$ saison. Or, si le parallèle n'est pas parfait entre croissance des champignons et longueur de la réaction, la liaison est en revanche quasiment

Tableau I. Sur arbres vivants, liaisons entre distances d'arrêt des champignons dans le phloème, quantité totale de résine dans la réaction à la date d'arrêt du champignon et proportion de cellules de phloème imprégnées de résine sur des coupes histologiques localisées le plus près possible du point d'arrêt (10 ou $30 \mathrm{~mm}$ du point d'inoculation). Tableau établi d'après les données des figures 3,5 et 6 . (1) On n'observe qu'un ralentissement de croissance ; (2) date d'arrêt très incertaine.

\begin{tabular}{|c|c|c|c|c|c|c|c|c|c|c|c|c|}
\hline & \multicolumn{4}{|c|}{$y^{r e}$ saison } & \multicolumn{4}{|c|}{$2^{\natural}$ saison } & \multicolumn{4}{|c|}{$3^{\circ}$ saison } \\
\hline & Ob & Oi & Om & Lw & $\mathrm{Ob}$ & $\mathrm{Oi}$ & Om & $L w^{(1)}$ & Ob & Oi & Om ${ }^{(2)}$ & Lw \\
\hline Date d'arrêt (j) & 30 & 30 & 30 & 30 & 7 & 14 & 14 & 14 & 14 & 14 & 30 & 14 \\
\hline Distance d'arrêt (mm) & 10 & 10 & 25 & 25 & 13 & 25 & 45 & 30 & 15 & 15 & 25 & 25 \\
\hline Résine totale (mg) & 20 & 10 & 140 & 115 & 50 & 60 & 160 & 280 & 80 & 50 & 300 & 450 \\
\hline \multicolumn{13}{|c|}{ \% cellules imprégnées de résine : } \\
\hline - à $10 \mathrm{~mm}$ & 40 & 10 & - & - & 20 & - & - & - & 35 & 45 & - & - \\
\hline - à $30 \mathrm{~mm}$ & - & - & 70 & 55 & - & 25 & 40 & 50 & - & - & 65 & 60 \\
\hline
\end{tabular}


respectée quand, au lieu de la longueur de la réaction, on s'intéresse aux quantités totales de résine synthétisées, ce qui suggère que les quantités de résine sont fonction de la quantité d'éliciteur produite suite à la croissance des champignons. Les différences que nous venons d'évoquer entre $3^{\theta}$ et $2^{\theta}$ saisons s'expliqueraient donc plutôt par des différences dans le pouvoir éliciteur des champignons eux-mêmes.

Peut-être alors faut-il rechercher l'explication de ces différences dans le fait qu'en $3^{\theta}$ saison l'arbre a totalement terminé sa croissance et que ses ressources énergétiques peuvent alors être mobilisées plus efficacement qu'en $2^{\theta}$ saison pour des facteurs liés à la défense de l'organisme. En $1^{r \theta}$ saison, l'arbre n'est pas en croissance non plus, mais ses ressources pourraient malgré tout ne pas être mobilisables pour la défense en raison de températures peu élevées, auxquelles s'ajoute le fait que l'on se trouve en période de repos végétatif. C'est de même en faisant appel au principe de la balance entre croissance et différenciation avancé par Loomis $(1932,1953)$ que Lorio (1986) explique les variations du succès des attaques du scolyte Dendroctonus frontalis Zimm dans le sud des Etats-Unis.

Un suivi régulier tout au long de l'année des capacités de défense du pin sylvestre, en liaison avec les phases d'activité et de croissance de l'arbre et avec les périodes d'attaque des insectes, permettrait de préciser ces points. L'apparition plus précoce du bourrelet cicatriciel en $3^{\ominus}$ saison qu'en $2^{\theta}$ et $1^{r \theta}$ saisons va dans le sens de ces considérations, de même que les délais de réponse plus courts en $3^{\theta}$ saison, qu'il s'agisse des dates d'apparition des réactions ou des dates d'atteinte des maxima. Les niveaux de réponse sont toutefois les plus élevés en $2^{\circ}$ saison, ce qui peut s'expliquer simplement par la plus longue persistance des conditions de température favorables, compensant ainsi la moindre disponibilité des ressources à cette époque par rapport à la $3^{\ominus}$ saison.
Comme on l'a vu plus haut, le parallélisme entre croissance des champignons et augmentation des quantités de résine suggère que ces dernières sont fonction des quantités d'éliciteurs produites suite à la croissance des champignons. Cela implique aussi que l'atteinte du plateau en quantité de résine corresponde à un épuisement de l'élicitation. Ainsi, en $3^{\theta}$ saison, ce plateau est atteint pour tous les champignons peu après que ceux-ci aient stoppé leur croissance. En $2^{\circ}$ saison, il en est de même sauf pour $L w$ pour lequel la quantité de résine augmente sans cesse pendant $60 \mathrm{j}$; mais dans ce cas la croissance du champignon est également continue pendant la même période. En $1^{\text {re }}$ saison, il n'y a pas de plateaux pour les quantités de résine accumulées, mais la croissance des champignons dure au moins jusqu'au $30^{\circ} \mathrm{j}$.

En fait, l'arrêt de l'accumulation de résine pourrait a priori correspondre aussi à une saturation des tissus ou à un épuisement des capacités de défense. Si tel était le cas cependant, il ne devrait pas exister de différences selon les champignons et les saisons dans le niveau des plateaux des courbes de concentration en résine dans la zone $0-20 \mathrm{~mm}$, ni dans la concentration finale en résine à $60 \mathrm{j}$, évaluée dans l'ensemble de la réaction (tableau II). En revanche, le moment où est atteint le plateau de concentration en résine dans la zone $0-20 \mathrm{~mm}$ correspond à peu près au moment où le champignon dépasse la zone considérée ou s'arrête de croître (tableau III), ce qui s'accorde tout à fait avec l'hypothèse que l'arrêt de l'accumulation de résine est dû à un épuisement de l'élicitation.

II devient alors intéressant de confronter la cinétique d'extension de la réaction de défense et la cinétique d'accumulation totale de la résine.

Deux situations sont à distinguer :

La première correspond à un arrêt de l'extension de la réaction avant celui de l'accumulation de résine, donc un retard de la synthèse et de la réaction résinique sur la croissance de la réac-

Tableau II. Concentration finale en résine dans la réaction totale, $60 \mathrm{j}$ après les inoculations (en mg de résine par $\mathrm{g}$ de phloème frais).

$O b=$ Ophiostoma brunneo-ciliatum ; Oi = Ophiostoma ips ; Om = Ophiustoma minus ; Lw = Leptographium wingfieldii ; $H d=$ Hormonema dematioides $; \mathrm{T}=$ inoculation témoin.

\begin{tabular}{llllllllllll}
\hline & & & \multicolumn{2}{c}{ Hd } & Ob & Oi & Om & Lw \\
\hline $1^{\text {re } \text { saison }}$ & 26 & \pm 27 & 25 & \pm 12 & $65 \pm 11$ & $111 \pm 158$ & $145 \pm 58$ & $155 \pm 115$ \\
$2^{\circ}$ saison & 42 & \pm 39 & $48 \pm 50$ & $171 \pm 162$ & $140 \pm 87$ & $151 \pm 83$ & $236 \pm 145$ \\
$3^{\circ}$ saison & $43 \pm$ & \pm 3 & $75 \pm 75$ & $113 \pm 58$ & $127 \pm 44$ & $132 \pm 13$ & $270 \pm 175$ \\
\hline
\end{tabular}


Tableau IIt. Comparaison des dates d'atteinte (nombre de jours) de la concentration maximale de résine dans la zone 0-20 $\mathrm{mm}$ et de la date de passage (nombre de jours) du front de champignon à $20 \mathrm{~mm}$ du point d'inoculation.

Tableau établi d'après les données des figures 3 et $4 . O b=$ Ophiostoma brunneo-ciliatum; Oi=Ophiostoma ips; $O m=$ Ophiostoma minus ; $L w=$ Leptographium wingfieldii. (1) Pas de plateau pour la concentration en résine, front de champignon toujours inférieur à $20 \mathrm{~mm}$, arrêt de la croissance à $30 \mathrm{j}$. (2) Front toujours inférieur à $20 \mathrm{~mm}$, arrêt de la croissance à $7 \mathrm{j}$. (3) Front toujours inférieur à $20 \mathrm{~mm}$, arrêt de la croissance à $14 \mathrm{j}$.

\begin{tabular}{|c|c|c|c|c|c|c|c|c|c|c|c|c|}
\hline & \multicolumn{4}{|c|}{$\gamma^{r e}$ saison } & \multicolumn{4}{|c|}{$2^{\circ}$ saison } & \multicolumn{4}{|c|}{$3^{e}$ saison } \\
\hline & $\mathrm{Ob}{ }^{(1)}$ & Oi (1) & Om & Lw & $\mathrm{Ob}$ & Oi & Om & Lw & $O b$ & $\mathrm{Oi}$ & Om & $L w$ \\
\hline $\begin{array}{l}\text { Date plateau } \\
\text { concentration } \\
\text { résine } 0-20 \mathrm{~mm} \mathrm{(j)}\end{array}$ & - & - & 30 & 30 & 14 & 14 & 7 & 14 & 14 & 14 & 14 & 30 \\
\hline $\begin{array}{l}\text { Date passage } \\
\text { front de champignon } \\
\text { à } 20 \mathrm{~mm} \text { (j) }\end{array}$ & - & - & 30 & 30 & 12 & $-(2)$ & 7 & 11 & $-{ }^{(3)}$ & $-(3)$ & 12 & 24 \\
\hline
\end{tabular}

tion. Ces situations sont observées pour tous les champignons en $1^{\text {re }}$ saison, pour $O$ minus en $3^{3}$ et pour $L$ wingfieldii aux 3 saisons.

Deux explications sont à envisager. En $1^{r e}$ saison, l'éliciteur diffuserait et commencerait à induire une réaction, mais les températures relativement basses et la faible activité de l'arbre ne permettraient qu'une synthèse très lente qui durerait longtemps. Dans le cas de $O m$ et de $L w$, leur agressivité très élevée en particulier en $2^{e}$ et en $3^{\theta}$ saison, induirait une accumulation si rapide et importante d'éliciteur, que la synthèse et la réaction résinique ne suivraient pas. Ce dernier phénomène pourrait être causé par un épuisement rapide des réserves locales et par la nécessité d'un certain délai pour mobiliser les réserves situées à distance. Bien que les mécanismes en soient différents, ces explications supposent toutes deux une accumulation de l'éliciteur.

La $2^{\mathrm{e}}$ situation concerne tous les autres cas, pour lesquels on constate que l'accumulation totale de résine s'arrête en même temps que la croissance de la réaction. Sur l'ensemble de celle-ci, la synthèse suit donc l'élicitation. Cela n'excluerait cependant pas qu'il puisse éventuellement se produire des accumulations locales d'éliciteurs et donc de résine, une homogénéisation pouvant intervenir ultérieurement.

L'examen histologique de l'évolution du pourcentage de tissu imprégné de résine au niveau de la partie médiane de la réaction nous fournit à ce sujet des informations complémentaires.

Par rapport au point d'inoculation, la localisation de cette zone médiane évolue, bien entendu, avec la croissance de la réaction. Sur 2 (ou plusieurs) mesures successives au niveau de ces zones médianes (dont les localisations sont différentes) une diminution ou une stabilisation du taux des cellules imprégnées indique que la vitesse de croissance en longueur de la réaction est supérieure ( $s^{\prime} i l$ y a diminution) ou égale (si stabilisation) à la vitesse d'accumulation de la résine. Une remontée ultérieure de ce taux est l'indice d'un «rattrapage».

Or de telles diminutions suivies de rattrapages se produisent très fréquemment, même dans les cas où, globalement, il n'y a pas de retard de l'accumulation résinique sur la croissance de la réaction. II semble donc en fait que la diffusion très rapide de l'éliciteur soit la règle, et qu'un gradient de la teneur en résine existe dans toutes les réactions, tant que leur croissance en longueur se poursuit. L'existence de ce gradient est d'ailleurs corroborée par la linéarité de l'accumulation de résine totale. Cette linéarité signifie en effet que l'arbre produit régulièrement de la résine au cours du temps sur l'ensemble de la réaction, au moins pendant la phase de croissance de celle-ci. Si donc cette croissance est rapide, ce qui provoque une sollicitation de plusieurs points à la fois, l'arbre répartit nécessairement sa réponse dans l'espace et dans le temps, ce qui conduit à l'établissement d'un gradient de teneur en résine à l'intérieur de la réaction. Ce gradient peut varier selon le champignon ou selon la saison ; il suffit pour s'en rendre compte de comparer par exemple les cinétiques d'accumulation de résine totale et de croissance en longueur des réactions dirigées contre $L w$ et $O m$.

Le "rattrapage" qui a lieu par la suite pourrait correspondre à une poursuite des synthèses résiniques dans les situations où l'éliciteur s'est accumulé, telles que celles des champignons très agressifs ( $L w$ et $O m$ ) ou celles de toutes les espèces lors de la $1^{\text {re }}$ saison. Dans ces cas en effet, ainsi qu'il est dit plus haut, la quantité totale de résine augmente encore après l'arrêt de la croissance de la réaction. 
II pourrait correspondre dans les autres situations, celles où l'accumulation globale de résine s'arrête en même temps que la croissance de la réaction, à une redistribution de la résine dans la réaction par diffusion à partir des zones très riches vers les zones moins concentrées. Cette homogénéisation conduirait à l'imprégnation de nouvelles cellules. La résine pourrait avoir son origine sur place, par exemple dans le cas des zones proches du point d'inoculation, ce qui expliquerait que le taux de cellules imprégnées à $10 \mathrm{~mm}$ du point d'inoculation, augmente après un plateau alors que la concentration locale n'augmente pas. Dans le cas de la zone médiane et sans doute de l'extrémité de la réaction, elle pourrait aussi provenir d'une autre zone de la réaction.

\section{Les paramètres de la réaction de défense}

L'existence d'un gradient de la teneur en résine, variable de surcroît selon l'espèce du champignon ou selon la saison, rend peu intéressante en tant que critère de mesure de l'importance de la réaction, toute utilisation d'une quantité de résine en un point précis. Nous ne pouvons donc retenir ici, ni la concentration en résine, ni le taux de cellules imprégnées à une distance donnée du point d'inoculation. Le taux de cellules imprégnées au niveau de la zone médiane ne présente pas ces inconvénients, mais son augmentation est très irrégulière; en outre, comme nous venons de le voir dans le cas des coupes réalisées à $10 \mathrm{~mm}$, des proportions différentes de cellules imprégnées peuvent correspondre à des quantités semblables de résine, et l'inverse est sans doute aussi possible.

En revanche, la quantité cumulée de résine sur toute la réaction, ainsi que la longueur de cette dernière, présentent une croissance linéaire au cours du temps jusqu'à l'atteinte de leur plateau, c'est-à-dire, selon les champignons et les saisons, jusqu'à 14 à $30 \mathrm{j}$ après la date d'inoculation. Ces critères s'avèrent être les plus représentatifs de l'importance de la réaction et c'est à partir d'eux que l'on peut tenter une définition des divers paramètres de celle-ci. Le fait que la croissance de la réaction puisse être terminée tandis que la résine continue à s'accumuler nous fera toutefois préférer, quand cela sera possible, l'utilisation de la quantité cumulée de résine. La validité de ce choix est confortée par le parallélisme d'évolution de ce dernier critère et de la croissance des champignons.

En conséquence, nous proposons de définir la réaction de défense du phloème par les paramètres suivants :
- La rapidité sera déterminée par l'inverse du délai de réponse, c'est-à-dire du temps nécessaire à l'apparition, après l'agression, d'une quantité de résine supérieure à celle des témoins.

- L'intensité sera représentée par la pente de la partie linéaire de la courbe exprimant la cinétique de croissance de la quantité totale de résine. Elle présente l'avantage de pouvoir se mesurer n'importe quand entre le délai de réponse et la date d'atteinte du plateau, c'est-à-dire entre 1 à $7 \mathrm{j}$ et 14 à $30 \mathrm{j}$ après inoculation. Sa connaissance nécessite en principe deux mesures espacées dans le temps, mais une seule pourra suffire dans le cas d'études comparatives où l'on pourra se contenter de valeurs relatives.

- L'efficacité pourrait, de façon simple, être définie par l'inverse du délai nécessaire à l'apparition du bourrelet cicatriciel, ou par l'inverse de la quantité totale de résine accumulée au moment de l'arrêt de croissance du champignon ou au moment de la formation du bourrelet. Toutefois, la synthèse de résine est un processus coûteux en énergie (Croteau et al, 1972 ; Croteau et Loomis, 1975). Dans le cas d'attaques massives de scolytides, une demande de synthèse importante et répartie en de multiples points peut avoir pour conséquence une insuffisance dans la mobilisation de toutes les ressources nécessaires au développement des réactions de défense, et par suite permettre l'installation de la population du déprédateur (Raffa, Berryman, 1983 ; Christiansen et al, 1987). Puisqu'elle est un reflet de la quantité d'énergie mobilisée, la quantité totale de résine synthétisée est donc à prendre en considération pour l'estimation de l'efficacité de la réaction. En outre, la réaction résinique provoque la mort de toutes les cellules imprégnées de résine, lesquelles peuvent ensuite entraver la circulation de l'eau et des éléments nutritifs. II importe donc de tenir compte également de la quantité de tissus mobilisés et condamnés pour estimer l'efficacité de la réaction. La longueur de la réaction et la quantité de résine renseignent finalement sur l'intensité du combat entre l'arbre et son agresseur.

Pour ces raisons, nous proposons de définir l'efficacité de la réaction comme l'inverse du produit de la quantité totale de résine accumulée, par la longueur totale de la réaction au moment de l'arrêt de croissance du champignon. La valeur réelle de cette efficacité ne peut s'obtenir qu'après cet arrêt. Cependant, pour des études comparatives par exemple entre arbres pour un champignon donné, ou entre champignons pour un arbre donné, on pourra l'apprécier en valeur relative avant même cette date, à condition d'être sûr que l'agresseur sera jugulé, ce qui est tou- 
jours le cas lorsque l'arbre n'est pas l'objet d'un nombre très élevé d'attaques.

Considérant les attaques de scolytides et leurs champignons associés, nous avions précédemment considéré que ces derniers étaient d'autant plus agressifs qu'ils induisaient une réaction de défense plus étendue (Lieutier et al, 1989b). Dans ces conditions et pour des attaques destinées à avorter, nous pouvons proposer de définir l'agressivité d'un agresseur comme l'inverse de l'efficacité de la réaction. Ainsi par exemple, d'après les figures 3 et 5 , c'est en $1^{\text {re }}$ saison que les réactions sont les plus efficaces et en été que les champignons sont les plus agressifs.

\section{REMERCIEMENTS}

Cette étude a été réalisée dans le cadre de l'ATP CNRS-INRA $n^{\circ} 4320$ et grâce à un financement du Conseil Régional de la Région Centre. Les auteurs remercient l'Office National des Forêts, Direction Régionale Centre et Centre de Gestion d'Orléans, pour la mise à disposition des parcelles d'études.

\section{RÉFÉRENCES}

Berryman AA (1972) Resistance of conifers to invasion by bark beetle-fungus associations. Bioscience 22 , 599-601

Christiansen E (1985) Ceratocystis polonica inoculated in Norway spruce : blue-staining in relation to inoculum density, resinosis and tree growth. Eur $J$ For Pathol 15, 160-167

Christiansen E, Horntvedt R (1983) Combined Ips/Ceratocystis attack on Norway spruce, and defensive mechanisms of the trees. $Z$ Angew Entomol 96, 110-118

Christiansen E, Waring $\mathrm{RH}$, Berryman AA (1987) Resistance of conifers to bark beetle attack : searching for general relationship. For Ecol Manage 22, 89-106

Croteau R, Burbott AJ, Loomis WD (1972) Apparent energy deficiency in mono- and sesquiterpene biosynthesis in peppermint. Phytochemistry 11, 2 9372948

Croteau R, Loomis WD (1975) Biosynthesis and metabolism of monoterpenes. Int Flavours Food Addit 6, 292-296

Horntvedt R, Christiansen E, Solheim H, Wang SG (1983) Artificial inoculation with Ips typographus associated blue-stain fungi can kill healthy Norway spruce trees. Medd Nor inst Skogforsk 38, 1-20

Johansen DA (1940) Plant microtechnique. Mc Graw Hill, New York

Lieutier F, Berryman AA (1988) Preliminary histological observations of the defense reactions of three pines to Ceratocystis clavigera and two chemical elicitors. Can J For Res 18, $1243-1247$
Lieutier F, Ferrell GT (1988) Relationships between indexes of tree vigour and the induced defense reaction of scots pine to a fungus associated with Ips sexdentatus (Coleoptera : Scolytidae). Proc XVIIIth Intern Congr Entomol, Vancouver, 3-9 July, 163-178

Lieutier F, Yart A (1989) Preferenda thermiques des champignons associés à lps sexdentatus Boern et Tomicus piniperda L (Coleoptera : Scolytidae). Ann Sci For 46, 411-415

Lieutier F, Cheniclet C, Garcia J (1989a) Comparison of the defense reactions of Pinus pinaster and Pinus sylvestris to attacks by two bark beetles (Coleoptera : Scolytidae) and their associated fungi. Environ Entomol 18, 228-234

Lieutier F, Yart A, Garcia J, Ham MC, Morelet M, Levieux $J(1989 b)$ Champignons phytopathogènes associés à deux coléoptères Scolytidae du pin sylvestre (Pinus sylvestris $L$ ) et étude préliminaire de leur agressivité envers l'hôte. Ann Sci For 46, 201-216

Loomis WE (1932) Growth-differentiation balance vs carbohydrate-nitrogen ratio. Proc Am Soc Hortic Sci 29, 240-245

Loomis WE (1953) Growth correlation. In : Growth and differenciation in plants (WE Loomis ed). lowa State College Press, Ames, IA, 197-217

Lorio PL (1986) Growth-differentiation balance. A basis for understanding southern pine-beetle-tree interactions. For Ecol Manage 14, 259-273

Lorio PL, Hodges JD (1985) Theories of interactions among bark beetles, associated microorganisms, and host trees. Proc 3rd biennal South Silvicul Res Conf, Atlanta, November 7-8, 1984. Gen Tech Rep SO-54, SFES, New Orleans, pp 485-492

Miller RH, Berryman AA (1986) Carbohydrate allocation and mountain pine beetle attack in girdled lodgepole pines. Can J For Res 16, $1036-1040$

Piou D, Lieutier F (1989) Observations symptomatologiques et rôles possibles d'Ophiostoma minus Hedgc (Ascomyces: Ophiostomatales) et de Tomicus piniperda L (Coleoptera : Scolytidae) dans le dépérissement du pin sylvestre en forêt d'Orléans. Ann Sci For 46, 39-53

Raffa KF, Berryman AA (1983) The role of host resistance in the colonization behavior and ecology of bark beetles. (Coleoptera : Scolytidae). For Ecol Manag 53, 27-49

Reid RW, Whitney HS, Watson JA (1967) Reactions of lodgepole pine to attack by Dendroctonus ponderosae Hopkins and bluestain fungi. Can $J$ Bot 45 , $1115-1126$

Safranyk L, Shrimpton DM, Whitney HS (1975) An interpretation of the interaction between lodgepole pine, the mountain pine beetle, and its associated blue stain fungi in western Canada. In : Management of Lodgepole Pine ecosystems. (DM Baumgartner ed), Pullman ; Wash State Univ Coop Ext serv, 406-428

Waring RH, Pitman GB (1980) A simple model of host resistance to bark beetles. Forest research Laboratory, Research note $65,2 \mathrm{p}$

Wright $E$ (1933) A cork-borer method for inoculating trees. Phytopathology 23, 487-488 